\title{
Adsorption and Corrosion Inhibition Effect of 2-Mercaptobenzimidazole (Surfactant) on a Carbon Steel Surface in an Acidic Medium: Experimental and Monte Carlo Simulations
}

\author{
F. El-Hajjaji ${ }^{a}$, M.E. Belghiti ${ }^{b}$, B. Hammouti ${ }^{b}$, S. Jodeh $^{c, *}$, \\ O. Hamed ${ }^{c}$, H. Lgaz ${ }^{d, e}$ and R. Salghi ${ }^{d}$ \\ ${ }^{a}$ Laboratory of Electrochemistry Engineering, Modetling and Environment (LIEME), \\ Faculty of Science/University-Sidi Mohammed Ben Abdellah, Fès, Morocco \\ ${ }^{b}$ Laboratory of Applied Chemistry, Materials and Environment (LC2AME), COSTE, \\ Faculty of Science, Oujda, Morocco \\ ${ }^{c}$ Department of Chemistry, An-Najah National University, P.O. Box 7, Nablus, Palestine \\ ${ }^{d}$ Laboratory of Applied Chemistry and Environment, ENSA, Ibn Zohr University, \\ P.O. Box 1136, 80000 Agadir, Morocco \\ ${ }^{e}$ Laboratory of Separation Processes, Faculty of Science, Ibn Tofail University, \\ P.O. Box 242, Kenitra, Morocco
}

Received June 12, 2017; accepted September 08, 2017

\begin{abstract}
Experimental electrochemical methods, combined with Monte Carlo simulations, have been employed to investigate the possibility of using 1-decyl-2-(decylthio)-1Hbenzimidazole (T2) as corrosion inhibitor for mild steel in a $1 \mathrm{M} \mathrm{HCl}$ medium. This inhibitor was found to be of the mixed type. The results derived from EIS indicate that the charge transfer resistance has increased with the increase in the inhibitor concentration. The inhibitory mechanism was explored by the potential of zero charge (Epzc) measurement at the solution/metal interface. The inhibitor adsorption has followed Langmuir adsorption isotherm. Surface morphology results showed the compound adsorbed film on a mild steel surface. The molecule interactions with the mild steel surface were simulated based on Monte Carlo simulation approach using $\mathrm{Fe}(111)$ crystal surface as a representative metallic surface.
\end{abstract}

Keywords: C-steel; $\mathrm{HCl}$; corrosion inhibitor; EIS; benzimidazole; Monte Carlo simulation.

\section{Introduction}

Corrosion is an electrochemical interaction between metals and the environment. It is an undesirable phenomenon, as it can cause severe harm to metals and alloy structures, and economic significances in terms of damaged products replacement. Among metals, steel is most widely used in industries, and it suffers

\footnotetext{
*Corresponding author. E-mail address: sjodeh@ @otmail.com
} 
from a certain type of corrosion within some environments. For instance, hydrochloric acid is one of the most aggressive industrial acids, and only few materials, such as glass, can withstand it. It is widely used as a solution for removing undesirable flaking and rusting at several industrial processes [5-7]. So, the industries that involve hydrochloric acid have to search for methods to insulate the steel and prevent it from getting onto a direct contact with $\mathrm{HCl}$. As a result, several approaches were developed for steel protection against corrosion [1-4]. One of the most acceptable approaches is the use of chemical inhibitors. The inhibitors function as an insulator for steel, preventing it from getting into contact with aggressive chemicals. Examples of chemical inhibitors are Ncontaining organic compounds, which have been widely used as corrosion inhibitors for different metals in distinct corroding media [8-10]. Surfactants have been also used for the same reason; they are composed of hydrophobic moiety and a hydrophilic head. The hydrophilic moiety of the surfactants adsorbs onto the metal surface, while the hydrophobic moiety extends into the solution phase.

Surfactant inhibitors are attractive, since they are available at reduced prices, have low toxicity, and some of them have showed high corrosion inhibition efficiency $[1-3,5,18]$.

The adsorption onto the metal surface can be interpreted in two ways: (I) chemical adsorption takes place through charge transfer amidst certain delocalized $\pi$-electrons of the molecule and the empty d-orbital of the iron area atom; (II) physical adsorption is carried out via the forces of Van der Waals or electrostatic attraction [11-15]. The combination of the azole ring with the surfactant compounds reinforces the inhibition process, which is interpreted by the intermolecular synergistic effect of various groups of the inhibitor [16-18].

The promising results obtained by a new surfactant called 1-tetradecyl-2(tetradecylthio)-1H-benzimidazole [19] have led us to prepare another one, 1decyl-2-(decylthio)-1H-benzimidazole (T2), in which the carbon chain was reduced from 13 to 9; this is the aim of the present study. Potentiodynamic polarization and EIS measurements, as well as SEM investigation and dynamic simulation, were used to explain the inhibitory action at the iron surface.

\section{Experimental details Synthesis of inhibitors}

To a solution of $2 \mathrm{~g}\left(133.10^{-4} \mathrm{~mol}\right)$ of 2-mercaptobenzimidazole and $80 \mathrm{~mL}$ of $N, N$-dimethylformamide, $3.67 \mathrm{~g}\left(266.10^{-4} \mathrm{~mol}\right)$ of potassium carbonate, $\left(133.10^{-4}\right.$ $\mathrm{mol})$ of tetra-n-butylammonium bromide and $8.8 \mathrm{~g}\left(399.10^{-4} \mathrm{~mol}\right)$ of 1 bromodecane were added. The reaction mixture was stirred at room temperature for 24 hours. After rearward filtration, the solvent was removed under reduced pressure. The residue was taken up in dichloromethane and filtered, and the solvent was evaporated under reduced pressure (Scheme 1). 


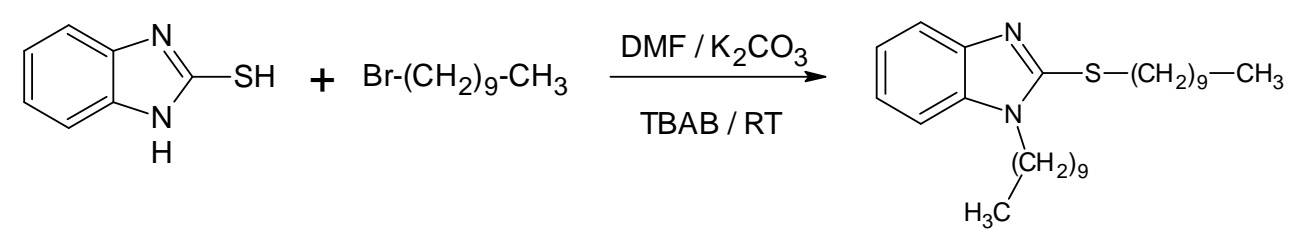

Scheme 1. Synthesis of 1-decyl-2-(decylthio)-1H-benzimidazole (T2).

This product was characterized by interpreting ${ }^{1} \mathrm{H}$ NMR, ${ }^{13} \mathrm{C}$ NMR and mass spectral data (Fig.1). Thus, the ${ }^{1} \mathrm{H}$ NMR spectrum taken in $\mathrm{CDCl}_{3}$ showed a multiple between $7.24 \mathrm{ppm}$ and $7.80 \mathrm{ppm}$ for the aromatic protons, triplet at 4.09 ppm for $\mathrm{NCH}_{2}$ and at 3.52 ppm for $\mathrm{SCH}_{2}$, a multiple between $1.24 \mathrm{ppm}$ and 1.84 ppm, corresponding to the protons carried by the methylene groups of the hydrocarbon chain, and a triplet at $0.86 \mathrm{ppm}$ for $\mathrm{CH}_{3}$.

Inversely, the ${ }^{13} \mathrm{C}$ NMR spectrum taken in $\mathrm{CDCl}_{3}$ presents a signal at $151.95 \mathrm{ppm}$ for the carbon bonded to the sulfur atom, signals between $31.88 \mathrm{ppm}$ and 22.66 ppm corresponding to the carbon of the methylene groups, and signals at 14.11 ppm for $\mathrm{CH}_{3}$. The mass spectrum shows a molecular pic $[\mathrm{MH}]{ }^{+}$at $\mathrm{m} / \mathrm{z}=431$.
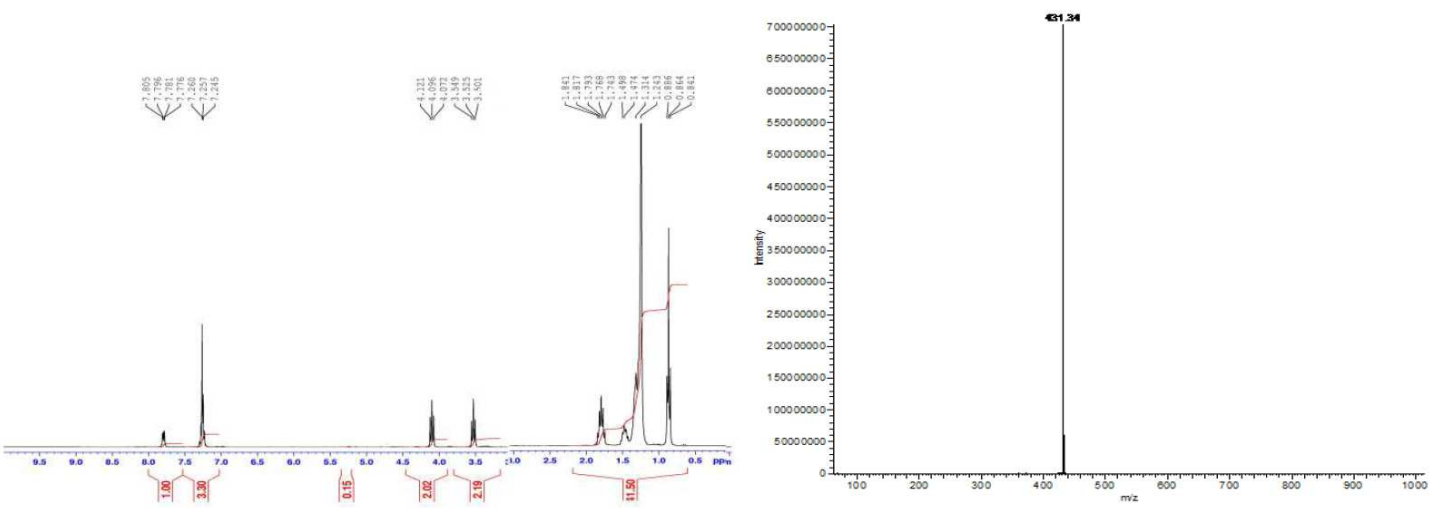

Figure 1. NMR ${ }^{1} \mathrm{H}$ and mass spectra of 1-decyl-2-(decylthio)-1H-benzimidazole (T2). Yield $=93 \%, \mathrm{NMR}^{1} \mathrm{H}\left(\mathrm{CDCl}_{3}\right)(\delta \mathrm{ppm}): 0.86:\left(\mathrm{t}, 6 \mathrm{H},-\mathrm{CH}_{3}\right) ; 1.24-1.84:(\mathrm{m}, 32 \mathrm{H},-$ $\mathrm{CH}_{2}$ ); 3.52: (t, 2H, SCH 2$)$; 4.09: (t, 2H, $\left.\mathrm{NCH}_{2}\right)$; 7.24-7.80: $(\mathrm{CH}$ benzene) (m, 4H). $\mathrm{NMR}^{13} \mathrm{C}\left(\mathrm{CDCl}_{3}\right)(\delta \mathrm{ppm}): 14.11:\left(\mathrm{CH}_{3}\right) ; 22.66-31.88:\left(-\mathrm{CH}_{2}\right) ; 33.14:\left(\mathrm{SCH}_{2}\right) ; 44.57$ : $\left(\mathrm{NCH}_{2}\right)$; 109.04-135.05: $(\mathrm{CH}$ benzene); 151.95: $(\mathrm{C}=\mathrm{N})$. Mass spectrometry presents a pic $[\mathrm{MH}]^{+}$at $\mathrm{m} / \mathrm{z}=431$.

\section{Electrochemical experiments}

A set of three-electrode cells containing C-steel coupons with a surface of $1 \mathrm{~cm}^{2}$ was incorporated in the specimen holder as working electrode (WE); a large area platinum mesh was used as counter electrode (CE), and saturated calomel as reference electrode $(\mathrm{RE})$. Electrochemical experiments were conducted at room temperature $(308 \pm 2 \mathrm{~K})$ using $100 \mathrm{~mL}$ of $1 \mathrm{M} \mathrm{HCl}$ electrolyte in a stationary state. Before each potentiodynamic polarization (Tafel) and electrochemical impedance spectroscopy (EIS) experiments, the electrode was allowed to freely corrode, and its open-circuit potential (OCP) was written down as a function of time, for periods smaller than $30 \mathrm{~min}$, but for this time, there was a steady-state $\mathrm{OCP}$, corresponding to the corrosion potential $(\mathrm{E})$ of the working electrode that was obtained. The potentiodynamic Tafel measurements were initiated from the 
cathodic to the anodic mean, between $-800 \mathrm{mV}$ and $-200 \mathrm{mV}$, with a scan rate of $0.6 \mathrm{mV} / \mathrm{s}$. The above procedures were repeated for each $\mathrm{T} 2$ concentration.

Electrochemical impedance spectroscopy (EIS) measurements were carried out using ac signals of $10 \mathrm{mV}$ peak to peak amplitude, in the frequency range of $100 \mathrm{KHz}-10 \mathrm{MHz}$.

\section{Simulation details}

Monte Carlo (MC) simulations have been carried out using adsorption locator modules executed in the BIOVIA Material Studio 8.0 software, commercialized by Accelrys Inc. USA [20, 21]. Geometrical optimization of all compounds has been performed using a $\mathrm{DMol}^{3}$ module in the said software. The involved methodology and course of action using MC simulations can be found elsewhere [22-23]. The simulation of the interaction between the single inhibitor molecule (T2) in the neutral form and the iron (111) surface in an acidic medium was carried out in a simulation box $\left(3.517 \times 3.537 \times 4.026 \mathrm{~nm}^{3}\right)$ with periodic boundary conditions, to model a general case when the interface has any arbitrary boundary effects. The iron surface $\mathrm{Fe}(111)$ was first built and relaxed by minimizing its energy using molecular mechanics; then, it was increased, and its periodicity was changed by constructing a super cell $(7 \times 7 \mathrm{~nm})$ and, afterwards, a vacuum slab with $30 \AA$ thicknesses [24]. The whole simulation procedure has used COMPASS Force-Field [25-26], which is an ab-initio force field that makes accurate and simultaneous predictions of gas-phase and condensed-phase properties for a broad range of organic molecules; metal was used for all systems geometrical optimization [25]. The liquid phase, composed of 50 water molecules and $10 \mathrm{HCl}$ molecules, was added to simulate the impact of a solvent, since corrosion takes place in the solution.

\section{Results and discussion}

\section{Potentiodynamic polarization}

Both anodic and cathodic polarization curves of $\mathrm{C}$-steel in $1 \mathrm{M} \mathrm{HCl}$, for different concentrations of the prepared surfactant, are shown in Fig. 2.

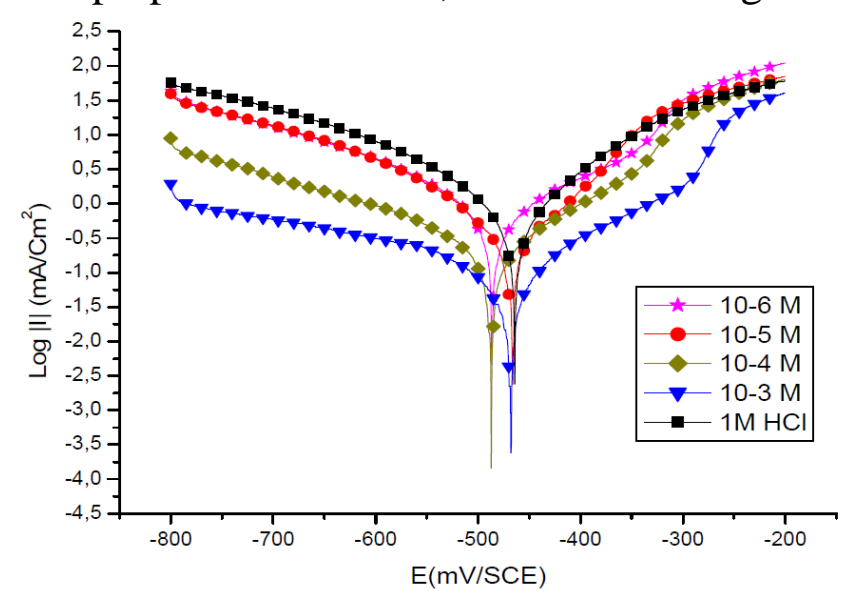

Figure 2. Tafel plots of C-steel immersed in $1 \mathrm{M} \mathrm{HCl}$, with or without $\mathrm{T} 2$.

It is clear that the inhibitor presence causes a distinguished decrease in the corrosion rate, that is, decreases the anodic and cathodic curves to lower current 
densities. This may be due to the inhibitor adsorption onto the corroded surface [26]. The values of the corrosion current densities ( $i_{\text {corr }}$ ), corrosion potentials $\left(\mathrm{E}_{\text {corr }}\right)$ and cathodic Tafel slopes $\left(\beta_{\mathrm{c}}\right)$ were calculated from Fig. 2, and are depicted in Table 1. From these results, it is clear that the corrosion current decreases with an increase in the inhibitor concentration. The anodic and cathodic branches change with the increase in the inhibitor concentration. For that reason, the prepared surfactant can be classified as a mixed-type inhibitor in $1 \mathrm{M} \mathrm{HCl}$.

The inhibition efficiency ( $\mathrm{E} \%$ ) was calculated by the following expression:

$$
E \%=\frac{i_{\text {corr }}-i_{\text {corr } / i n h}}{i_{\text {corr }}} \times 100
$$

where $i_{\text {corr }}$ and $i_{\text {corr } / i n h}$ are the corrosion current density of C-steel, with and without $\mathrm{T} 2$, respectively.

Table 1. Kinetic parameters derived from Tafel plots of C-steel immersed in $1 \mathrm{M} \mathrm{HCl}$ containing T2.

\begin{tabular}{ccccc}
\hline $\begin{array}{c}\text { Conc. } \\
(\mathbf{M})\end{array}$ & $\begin{array}{c}\mathbf{E}_{\text {corr }} \\
(\mathbf{m V} / \mathbf{S C E})\end{array}$ & $\begin{array}{c}\boldsymbol{i}_{\text {corr }} \\
\left(\boldsymbol{\mu} \mathbf{A . c m}^{-2}\right)\end{array}$ & $\begin{array}{c}\boldsymbol{\beta}_{\mathbf{c}} \\
(\mathbf{m V})\end{array}$ & $\begin{array}{c}\mathbf{E} \\
(\boldsymbol{\%})\end{array}$ \\
\hline $1 \mathrm{M} \mathrm{HCl}$ & -464 & 2102.7 & 160 & --- \\
$10^{-3}$ & -467 & 109 & 158 & 94 \\
$10^{-4}$ & -487 & 174 & 165 & 91 \\
$10^{-5}$ & -466 & 860 & 169 & 60 \\
$10^{-6}$ & -486 & 1053 & 173 & 50
\end{tabular}

The cathodic Tafel lines were almost parallel upon the increase in inhibitor concentrations, indicating that the hydrogen reduction in the metal surface is activation controlled, and that the mechanism is not impacted by the inhibitor presence [27]. The anodic and cathodic current densities are decreased in the inhibitor presence, while the corrosion potential is almost constant, and the change in $\mathrm{E}_{\text {corr }}$ value is around $20 \mathrm{mV} / \mathrm{SCE}$, indicating that the inhibitor acts as a mixed-type inhibitor.

Examination of Table 1 reveals that the cathodic Tafel slope $\left(\beta_{c}\right)$ shows slight changes with T2 addition, which suggests that the inhibiting action has occurred by simple blocking of the available cathodic sites on the metal surface, which has led to a decrease in the exposed area, necessary for hydrogen evolution. In addition, the inhibitory action increases with an increased inhibitor concentration. At a concentration of $10^{-3} \mathrm{M}$ or more, T2 acts as a good inhibitor in a hydrochloric acid solution, with an inhibition efficiency of about $94 \%$.

\section{Electrochemical impedance spectroscopy (EIS)}

The effect of each acid additive on the performance of T2 as a corrosion inhibitor for C-steel immersed in molar acid concentration was investigated by EIS experiment. The data obtained by EIS measurements are graphically represented by the Nyquist plot (Fig. 3) and the impedance parameters of each solution, such as polarization resistance $\left(\mathrm{R}_{\mathrm{p}}\right)$, double layer capacitance $\left(\mathrm{C}_{\mathrm{dl}}\right)$, and inhibition 
efficiency (IE \%)) are given in Table 2. The Nyquist impedance semicircles increase with an increased content of T2, indicating an increase in the diameter of the capacitive loop. T2 acts by adsorption, to cover the metal surface, and then retard the corrosion phenomenon [28].

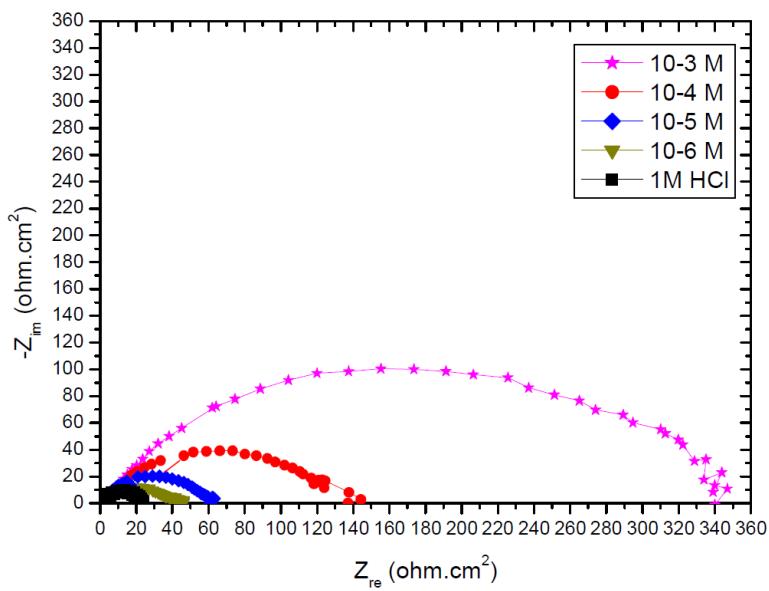

Figure 3. Impedance plots of C-steel in $1 \mathrm{M} \mathrm{HCl}$, with and without $\mathrm{T} 2$ at $308 \mathrm{~K}$.

Table 2. Kinetic parameters derived from EIS plots of C-steel in $1 \mathrm{M} \mathrm{HCl}$ containing $\mathrm{T} 2$ at $308 \mathrm{~K}$.

\begin{tabular}{ccccccc}
\hline $\begin{array}{c}\text { Concentration } \\
(\mathbf{m o l} / \mathbf{L})\end{array}$ & $\begin{array}{c}\mathbf{R} \mathbf{s} \\
\left(\boldsymbol{\Omega} . \mathbf{~ c m}^{2}\right)\end{array}$ & $\begin{array}{c}\mathbf{R} \mathbf{c t} \\
\left(\boldsymbol{\Omega} \mathbf{~ c m}^{2}\right)\end{array}$ & $\boldsymbol{n}$ & $\left.\begin{array}{c}Q \times 10^{-4} \\
\left(\mathrm{~S}^{n}\right.\end{array} \Omega^{-1} \mathbf{c m}^{-2}\right)$ & $\begin{array}{c}\mathbf{C}_{\mathbf{d l}} \\
\left(\boldsymbol{\mu} \mathbf{F} / \mathbf{c m}^{2}\right)\end{array}$ & $\begin{array}{c}\mathbf{I E} \\
(\boldsymbol{\%})\end{array}$ \\
\hline $1 \mathrm{M} \mathrm{HCl}$ & 2.02 & 23.26 & 0.88 & 2.4944 & 123 & - \\
$10^{-3}$ & 1.7 & 347 & 0.85 & 0.5777 & 28 & 93 \\
$10^{-4}$ & 1.5 & 134 & 0.87 & 0.7343 & 36 & 82 \\
$10^{-5}$ & 1.3 & 61 & 0.86 & 1.0544 & 46 & 62 \\
$10^{-6}$ & 0.7 & 44 & 0.84 & 1.7333 & 68 & 47 \\
\hline
\end{tabular}

The impedance diagrams are semicircles, due to the frequency dispersion [29-31] caused by the roughness and inhomogeneity of the electrode surface. The increase in T2 concentration leads to the increase of transfer resistance, as well as to the decrease of capacitance, as a result of the change in the dielectric properties and the thickness of the barrier-adsorbed film [32-34]. Impedance parameters such as the charge transfer, $R_{t}$, and the double layer capacitance, $C_{d l}$, are derived from Nyquist plots, and are gathered in Table 2, for C-steel in an hydrochloric acid solution, in the presence and absence of T2. The decreased values of double layer capacitance, $\mathrm{C}_{\mathrm{dl}}$, can be due to water molecules that are substituted by organic inhibitor molecules at the electrode interface of lower dielectric constant through adsorption [35].

The equivalent circuit model shown in Fig. 4 was used to analyse the EIS experiments. The parameters are collected in Table 2, while the double layer capacitance values are calculated using the Eq. (2): 


$$
C_{d l}=\sqrt[n]{\mathrm{Q}_{\mathrm{Rt}} \mathrm{R}^{1-\mathrm{n}}}
$$

where $\mathrm{Q}$ is the CPE constant and $\mathrm{n}$ is a coefficient that can be used as a measure of surface inhomogeneity [27]. The inhibition efficiency was calculated using the charge-transfer resistance values in the following equation:

$$
E \%=\frac{R_{t}^{\prime}-R_{t}}{R^{\prime}{ }_{t}} \times 100
$$

where $R_{t}$ and $R_{t}^{\prime}$ are the charge-transfer resistance values, without and with inhibitor, respectively.

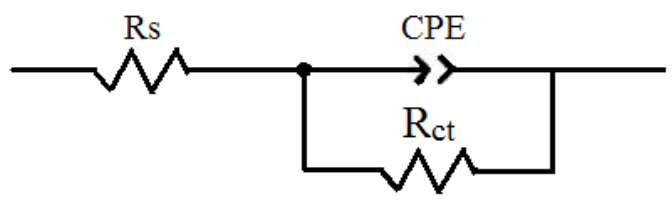

Figure 4. The electrochemical equivalent circuit used to fit the impedance spectra.

It is clear from the Table 2 data that $\mathrm{R}_{\mathrm{t}}$ increases with $\mathrm{T} 2$ concentration, which causes an increase in the corrosion inhibition efficiency $(\mathrm{E} \%)$. Double layer capacitance values are also brought down to the maximum extent in the inhibitors presence. The decrease in $\mathrm{C}_{\mathrm{dl}}$ is due to the adsorption of this compound onto the metal surface, leading to the formation of a film from the acidic solution [36-38].

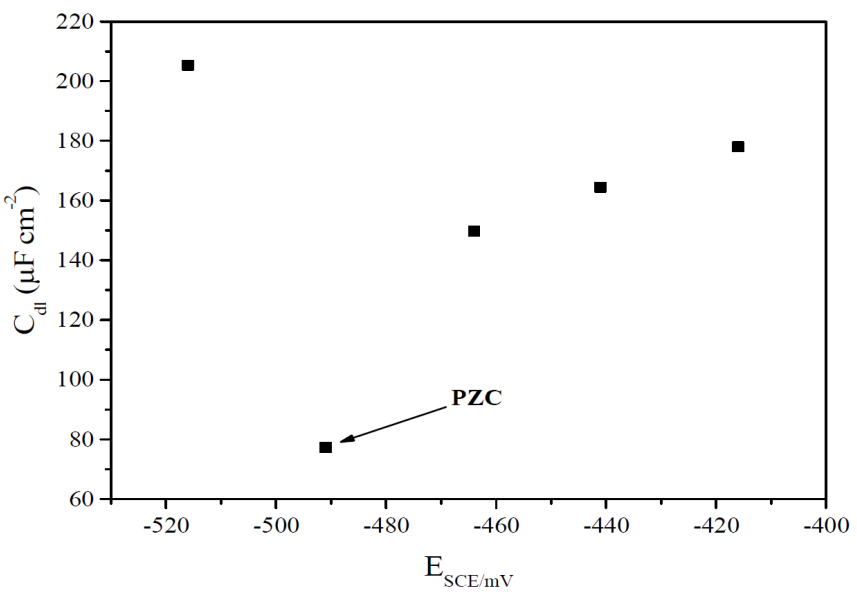

Figure 5. Plot of $\mathrm{C}_{\mathrm{dl}}$ vs. applied electrode potential (E, $\mathrm{mV}(\mathrm{SCE})$ ) in $1 \mathrm{M} \mathrm{HCl}$ containing $10^{-3} \mathrm{M} \mathrm{T} 2$.

\section{The potential of zero charge and the inhibition mechanism}

Corrosion inhibition mechanisms are interpreted by adsorption phenomena, which depend on the metal surface charge, the charge or dipole moment of the inhibitor ions/molecules, and the other ions that are specifically adsorbed onto the metal surface [39]. The metal surface charge is defined by the open circuit 
potential position, with respect to PZC [40]. The double layer capacitance value depends on the applied DC potential, which is graphically denoted in Fig. 5. It can be determined, according to Antropov et al. [41], by comparing the potential of zero charge (PZC) and the corrosion potential of the metal in the electrolytic medium. As PZC corresponds to a state where the surface is free from charges the stationary (corrosion) potential state -, the metal area will be positively or negatively charged. Hence, it is essential to have reliable data about PZC.

When carbon steel is immersed in an acidic solution containing T2, three kinds of species can be adsorbed onto its surface, as described below: (1) if the metal surface is positively charged with respect to PZC, at first, the chloride ions will be adsorbed onto the metal surface. Then, after this adsorption step, the steel surface will become negatively charged. Hence, the positively charged derived 2mercaptobenzimidazole cationic forms will form an electrostatic bond with the $\mathrm{Cl}^{-}$ions already adsorbed onto steel. Moreover, the excess positive charge on the electrode surface, $\Phi\left(\Phi=\right.$ EPZC - $\left.\mathrm{E}_{\text {corr }}\right)$ increases as more inhibitor molecules are adsorbed onto it [42]; (2) if the metal surface is negatively charged with respect to PZC, the protonated water molecules and derived 2-mercaptobenzimidazole cationic forms will be directly adsorbed onto the metal surface. Increasing negative charges on the metal surface leads to an increased adsorption of derived 2-mercaptobenzimidazole molecules, hence, its concentration in the solution should decrease; (3) when the metal obtains the potential at which the surface charge becomes zero, none of the ions (neither cations nor anions) adsorb onto the surface through their ionic center. However, a few indole molecules may be physically adsorbed through their planar $\pi$ orbitals onto the metal surface (with vacant $\pi$ orbitals).

In this study, EPZC $=-491 \mathrm{mV}$ and $\mathrm{E}_{\text {corr }}=-460 \mathrm{mV}$, for C-steel with the addition of $10^{-3} \mathrm{M}$ of T2. It can be said that $\Phi\left(\Phi=\mathrm{EPZC}-\mathrm{E}_{\text {corr }}\right)$ potential is positive in this case. From the above result, it follows that anions $\left(\mathrm{Cl}^{-}\right.$ions) in an aqueous hydrochloric acid solution will be first adsorbed onto the $\mathrm{C}$-steel surface. After this first adsorption step, the C-steel surface will become negatively charged. Hence, the positively charged 2-mercaptobenzimidazole derivative cationic forms will form an electrostatic bond with the $\mathrm{Cl}^{-}$ions already adsorbed onto the steel surface.

\section{Adsorption isotherm and adsorption parameters}

The adsorption isotherms provide basic information about the interaction between the inhibitor and the C-steel surface. Attempts were made to fit the experimental data to various isotherms, including Langmuir, Frumkin, Temkin, etc. It has been found that the experimental results for T2 in this study fit with Langmuir isotherm and the organic compound adsorption. The isotherm mostly used in biosensor research is the Langmuir isotherm, which is based on the following hypotheses: (i)-the surface supposed to be defined by a number of adsorption sites given by the surface concentration is totally covered; (ii)-there is an equilibrium between adsorbed and bulk target species and; (iii) there are no lateral interactions between the adsorbed target species [43]. 
Generally, the adsorption of an inhibitor occurs by two means: physisorption and/or chemisorption. The first one involves a weak undirected interaction, due to electrostatic attraction between inhibiting organic ions or dipoles and the electrically charged metal surface. The latter one occurs by sharing or charge transfer from the adsorbate to metal surface atoms, in order to form a coordinated bond; this interaction is known as chemical adsorption or chemisorption [44-46]. In order to obtain the adsorption isotherm, the degree of surface coverage $(\theta)$ for various inhibitor concentrations was calculated using the equation below, listed in Table 3.

$$
\theta=\frac{R_{t}^{\prime}-R_{t}}{R_{t}^{\prime}}
$$

Table 3. Adsorption parameters calculated from Langmuir isotherm.

\begin{tabular}{ccc} 
Inhibitor & $\mathbf{K}_{\text {ads }}(\mathbf{L} / \mathbf{m o l})$ & $\Delta G_{\text {ads }}^{\circ}(\mathbf{k J} / \mathbf{m o l})$ \\
\hline 145186.3 & 372202.64 & -40.72 \\
\hline
\end{tabular}

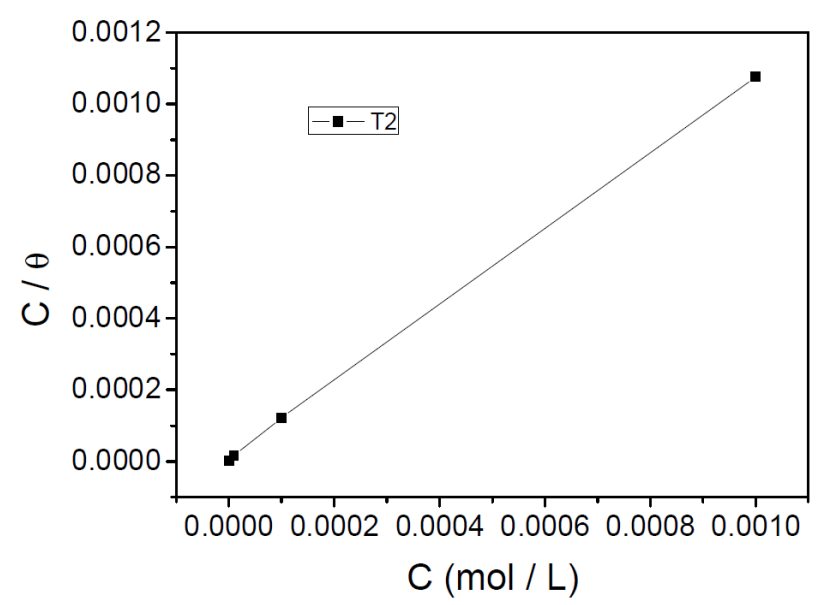

Figure 6. Langmuir adsorption isotherm model for $\mathrm{C}$-steel in $1 \mathrm{M} \mathrm{HCl}$ containing $\mathrm{T} 2$ at $308 \mathrm{~K}$ (EIS data).

Langmuir adsorption isotherm was tested for its fit (Fig.6) to the experimental data, and it is given by the following equation:

$$
\frac{C_{i n h}}{\theta}=\frac{1}{K_{a d s}}+C_{i n h}
$$

where $\mathrm{C}_{\mathrm{inh}}$ is the inhibitor concentration, $\mathrm{K}_{\mathrm{ads}}$ the adsorptive equilibrium constant, and $\theta$ represents the degree of adsorption.

The equilibrium constant for the adsorption process was related to the standard free energy of adsorption by the expression:

$$
\Delta G_{a d s}^{\circ}=-R T \operatorname{Ln}\left(55.5 K_{a d s}\right)
$$

where $\mathrm{R}$ is the gas constant, $\mathrm{T}$ is the experiment absolute temperature, and the constant value of 55.5 is the concentration of water in a solution in $\mathrm{mol} \mathrm{L}^{-1}$.

The plot of the $\left(\mathrm{C}_{\mathrm{inh}} / \theta\right)$ vs. $\mathrm{C}_{\mathrm{inh}}$ that fitted the experimental data follows well the Langmuir adsorption isotherm. The plot gives a straight line with a slope of 1.06 to close unity. The intercept that has obtained $6.8877 \times 10^{-6}$ is the reciprocal of 
$K_{a d s}$. This shows that the experimental data fit the isotherm. The values of $K_{a d s}$ and $\Delta \mathrm{G}_{\text {ads }}^{\circ}$ calculated from the isotherm model are listed in Table 3.

Generally, the energy values of $-20 \mathrm{~kJ} \mathrm{~mol}^{-1}$ or less are associated with an electrostatic interaction between charged molecules and charged metal surface, i.e., physisorption; but those with energy values of $-40 \mathrm{~kJ} \mathrm{~mol}^{-1}$ or less involve charge sharing or charge transferring from the inhibitor molecules to the metal surface, to form a coordinate covalent bond, i.e., chemisorption [47-49]. The value of $\Delta \mathrm{G}_{\mathrm{ads}}$ is equal to $-40.72 \mathrm{~kJ} \mathrm{~mol}^{-1}$. The large value of $\Delta \mathrm{G}_{\mathrm{ads}}$ and its negative sign is usually characteristic of a strong interaction and a highly efficient adsorption [50]. The high value of $\Delta \mathrm{G}_{\mathrm{ads}}$ shows that, in the presence of 1 $\mathrm{M} \mathrm{HCl,} \mathrm{T2} \mathrm{chemisorption} \mathrm{may} \mathrm{occur.} \mathrm{The} \mathrm{possible} \mathrm{conception} \mathrm{mechanisms} \mathrm{can}$ be attributed to the donation of $\pi$-electrons in the aromatic rings; the presence of two nitrogen atoms and one sulfur atom in an inhibitor molecule, as reactive centers, is an electrostatic adsorption of the protonated inhibitor compound in an acidic solution, onto the metal surface.

The results indicate that the increase in the inhibitor efficiency (IE\%) with an increased concentration may be attributed to the formation of a barrier film, which prevents the acidic medium from attacking the metal surface, due to the inhibitor adsorption (T2) onto the C-steel surface, involving interactions between the $\Pi$-electrons of the benzimidazole and phenyl rings heterocyclic structure, as well as $(-\mathrm{S}-,=\mathrm{N})$ between heteroatoms and iron surface atoms vacant orbitals (3d). We clearly assist to the intermolecular synergistic effect of various T2 adsorption centers [51].

\section{SEM investigation}

SEM photographs obtained from C-steel surface, after the specimen immersion in HCI (1 M) solution for $6 \mathrm{~h}$, in the absence and presence of $10^{-3} \mathrm{M}$ of T2, are shown in Fig. 7 (a) and (b).

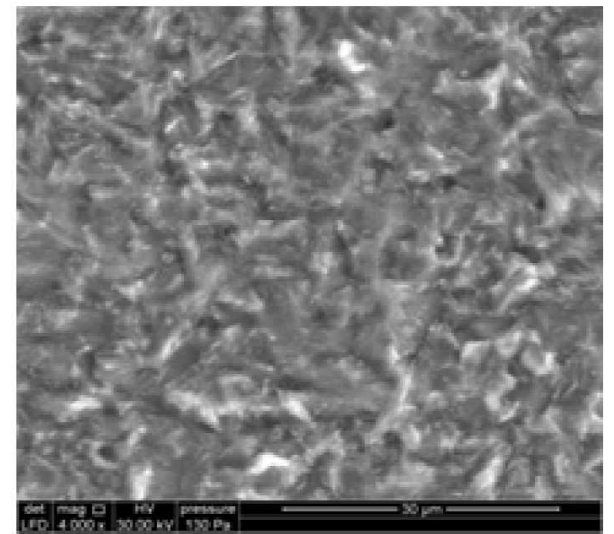

(a)

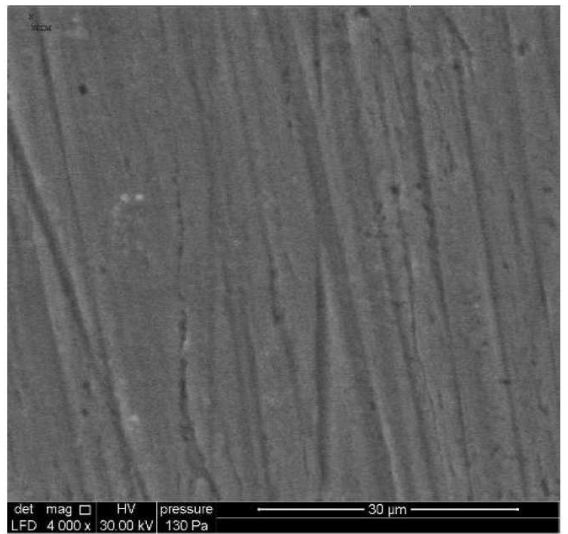

(b)

Figure 7. SEM photographs in the (a) absence and (b) presence of $10^{-3} \mathrm{M}$ of $\mathrm{T} 2$.

Fig. 7(a) shows that the C-steel surface was strongly damaged in hydrochloric acid, in the absence of T2 inhibitor; Fig. 7(b) shows that there is a good protective film against corrosion, adsorbed onto the C-steel surface, with $10^{-3} \mathrm{M}$ of $\mathrm{T} 2$. 


\section{Monte Carlo simulations}

MC simulation has emerged as a modern tool to investigate the adsorption behavior of a single inhibitor in the neutral form, on an iron surface in an acidic medium [21, 22]. MC simulation can reasonably predict the most favorable configuration of the adsorbed inhibitor molecule on the iron surface. The geometry optimization process is carried out using an iterative process, in which the atomic coordinates are adjusted until the total energy of a structure is minimized, i.e., it corresponds to a local minimum in the potential energy surface. The optimization energy curve of the inhibitor (T2), before putting it on the iron surface, is calculated by $\mathrm{DMol}^{3}$ module at m-GGA-M11-L/ DNP+ basis set, as presented in Fig. 8.

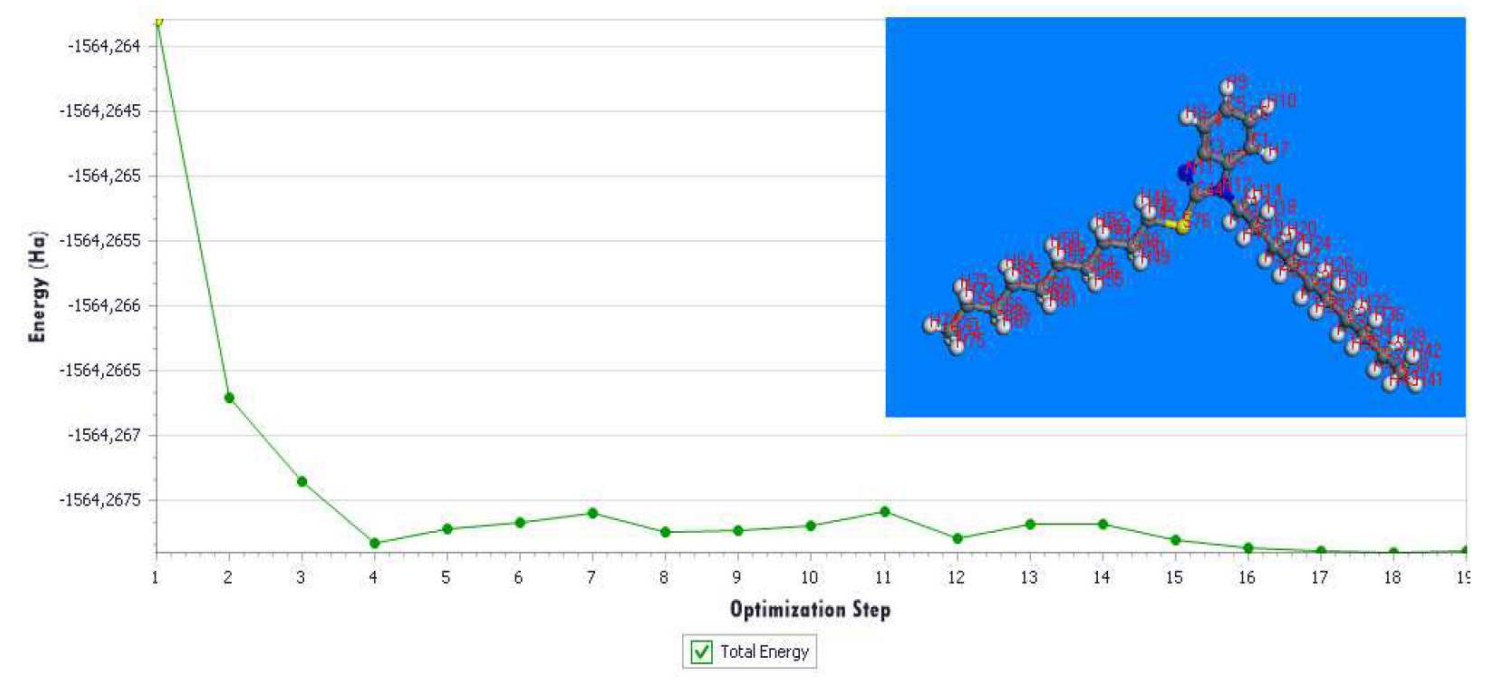

Figure 8. Optimization energy curve for the studied molecule, before putting it on the iron surface, using $\mathrm{DMol}^{3}$ module.

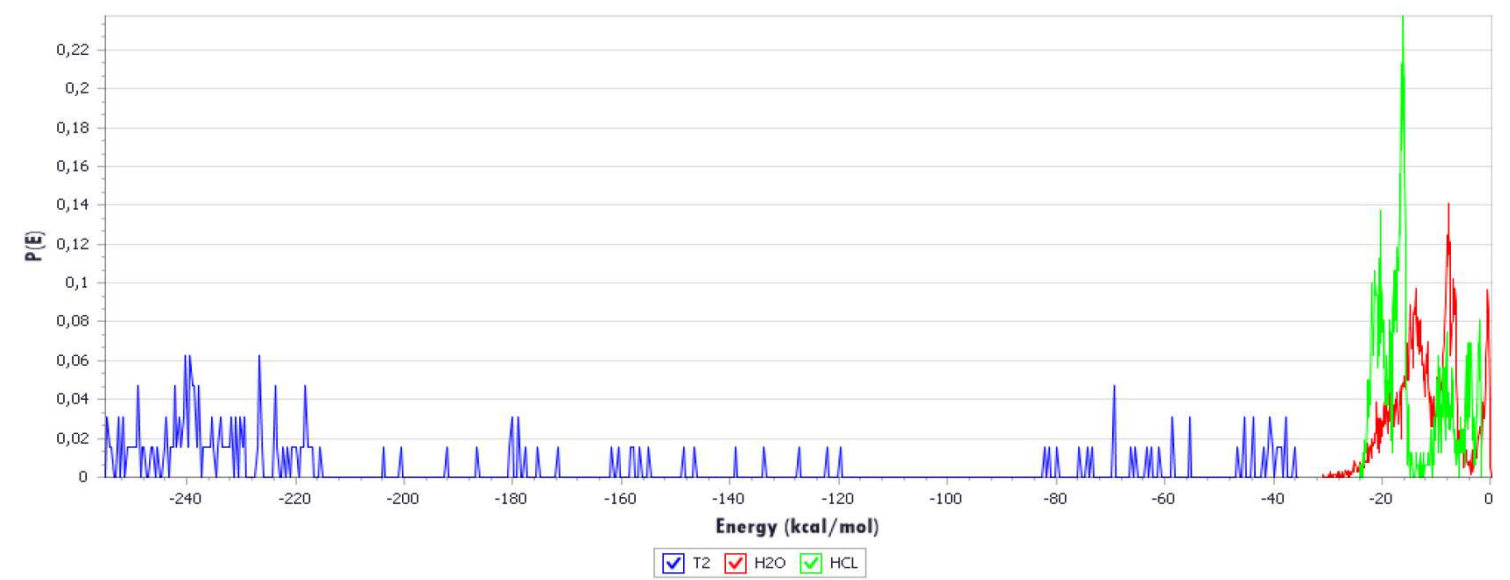

Figure 9. Adsorption energy distribution of T2 adsorbed on $\mathrm{Fe}(111)$ in the presence of $50 \mathrm{H}_{2} \mathrm{O}$ and $10 \mathrm{HCl}$.

T2 optimization energy curve in the neutral form was done using adsorption locator module. The adsorption energy distribution of T2 adsorbed on Fe (111) in 
the presence of $50 \mathrm{H}_{2} \mathrm{O}$ and $10 \mathrm{HCl}$, using adsorption locator module, is depicted in Fig. 9.

The selected inhibitor molecule (T2) was placed on the iron surface in a hydrochloric acid solution, optimized, and then run under quench molecular dynamics. A typical adsorption energy distribution of T2 adsorbed on Fe (111) in the presence of $50 \mathrm{H}_{2} \mathrm{O}$ and $10 \mathrm{HCl}$ consisting of the total energy, average total energy, Van der Waals energy, electrostatic energy and intermolecular energy, using Monte Carlo simulations, is depicted in Fig. 10.

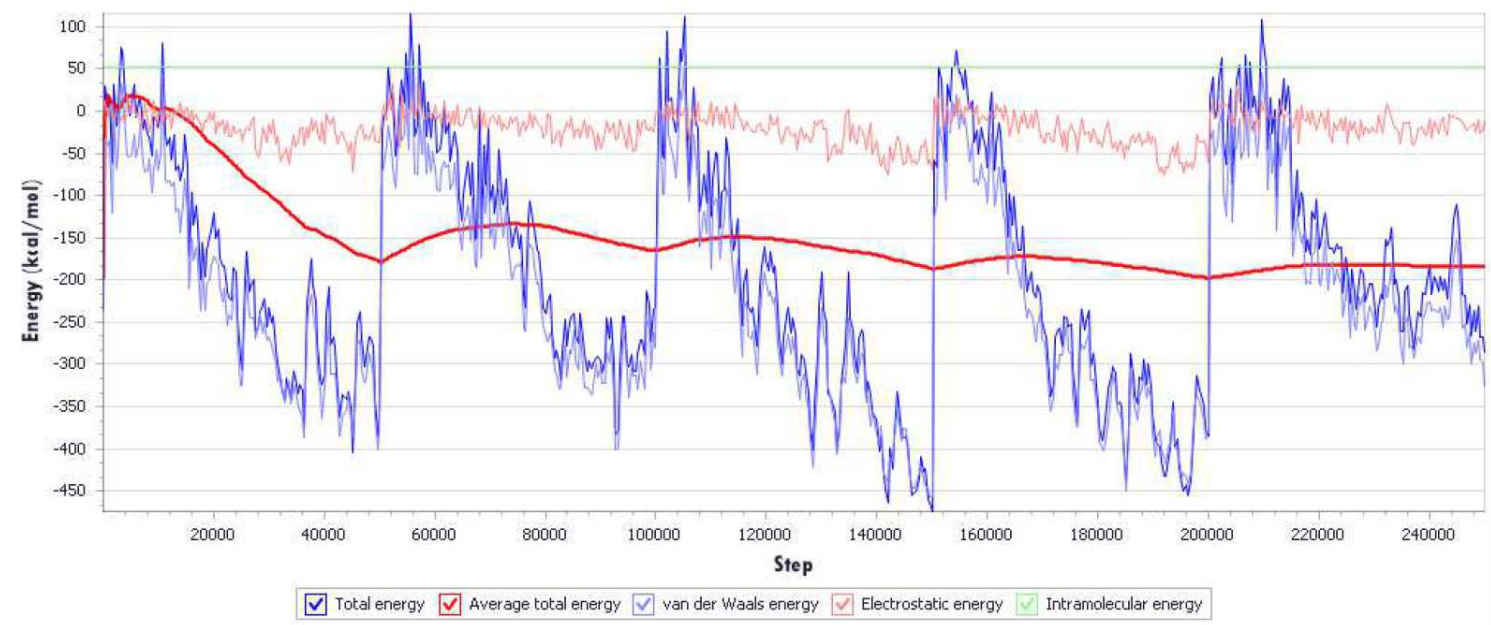

Figure 10. Typical energy profile for one molecule of T2 adsorbed on Fe (111) in the presence of $50 \mathrm{H}_{2} \mathrm{O}$ and $10 \mathrm{HCl}$.
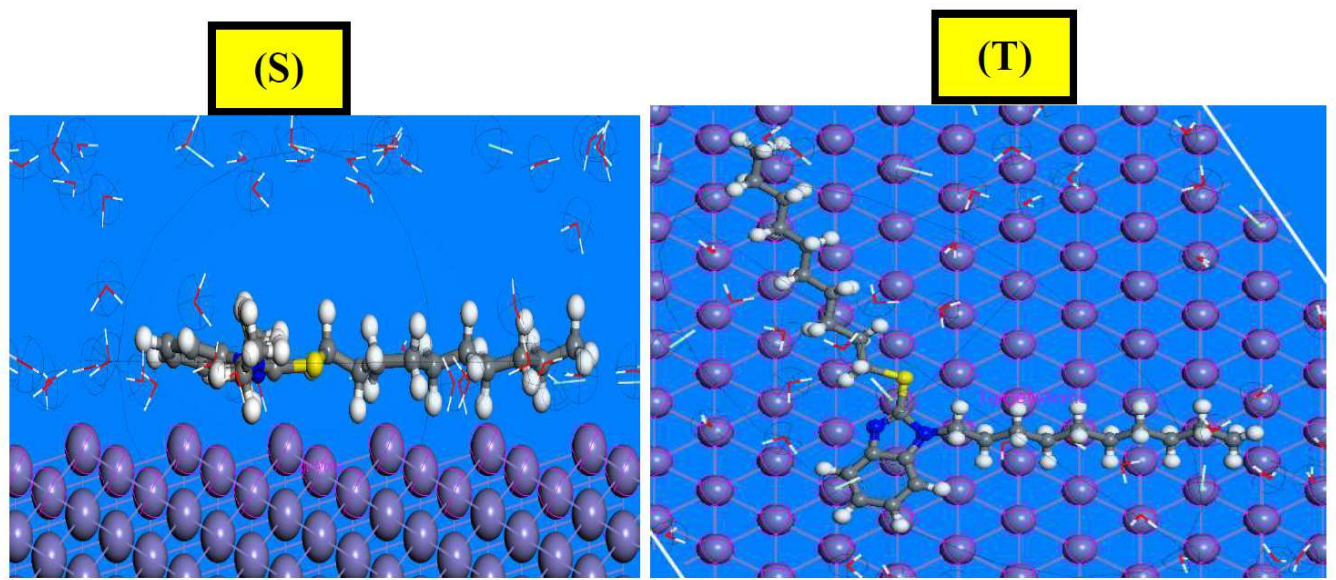

Figure 11. Equilibrium adsorption configurations obtained by adsorption locator module for one molecule of T2 adsorbed on $\mathrm{Fe}(111)$ in the presence of $50 \mathrm{H}_{2} \mathrm{O}$ and 10HCl. (T): top view; $(\mathrm{S})$ : side view.

The Metropolis Monte Carlo method in adsorption locator calculation provides four step types for a canonical ensemble: conformer, rotation, translation and regrowth [52]. Fig. 10 shows the most suitable inhibitor molecule conformation adsorbed onto the substrate (111), obtained by adsorption locator module (COMPASS Force Field) [25]. Side and top views of stable adsorption configurations of T2 adsorbed on $\mathrm{Fe}(111)$ in the presence of $50 \mathrm{H}_{2} \mathrm{O}$ and $10 \mathrm{HCl}$ using adsorption locator is given in Fig.11. 
The equilibrium configuration of $\mathrm{T} 2$ adsorbed on $\mathrm{Fe}$ (111) in the presence of $50 \mathrm{H}_{2} \mathrm{O}$ and $10 \mathrm{HCl}$ as well as the close contact of the Fe-inhibitor complex, are depicted in Fig. 11. T2 is adsorbed onto the Fe(111) surface in a hydrochloric acid solution, with almost parallel or flat dispositions. This flat orientation is possibly due to the formation of coordination and back bonding for the Feinhibitor (T2) complex. It is also herein evident that unoccupied iron orbitals (3d) will prefer to accept electrons from the adsorbed T2. T2 has a lone pair of electrons on the active centres $\left(=\mathrm{N} 1_{1^{-}},=\mathrm{N}_{12},-\mathrm{S}_{76^{-}}\right)$, as well as П-electrons in the benzimidazole ring. Those iron atoms and electrons (П) cloud in the aromatic rings provide sufficient electronic charge to the vacant orbitals (3d) of Fe, forming stable coordination bonds (chemisorption). The measured shortest bond distance between the closest heteroatoms $\left(=\mathrm{N}_{11^{-}},=\mathrm{N}_{12},-\mathrm{S}_{76^{-}}\right)$of the neutral form of T2 inhibitor and iron surface (111), in a hydrochloric acid solution at equilibrium, was as follows: Fe-inhibitor (T2) interaction: $\left(\mathrm{d}_{\mathrm{Fe}-\mathrm{S} 76-=3.294 \AA} \mathrm{d}_{\mathrm{Fe}-}\right.$

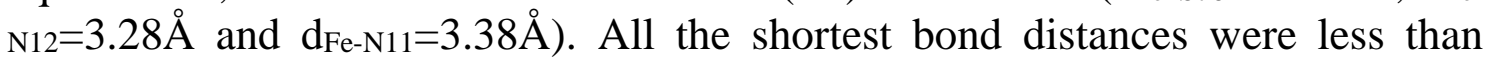
$3.55 \mathrm{~A}^{\circ}$, indicating a strong chemical bond formation between T2 and Fe (111) surface. However, vdW interactions were also involved in the adsorption process of the inhibitor with $\mathrm{Fe}$ (111). The outputs and descriptors using adsorption locator module, such as total adsorption, adsorption energy, rigid adsorption and deformation energies, are listed in Table 4.

Table 4. Outputs and descriptors using adsorption locator module for the lowest adsorption configurations of T2 adsorbed on Fe (111) in the presence of $50 \mathrm{H}_{2} \mathrm{O}$ and $10 \mathrm{HCl}$ (all values in $\mathrm{kcal} / \mathrm{mol}$ ).

\begin{tabular}{|c|c|c|c|c|c|c|c|}
\hline Structures & $\mathbf{E}_{\text {Total }}$ & $\mathbf{E}_{\text {ads }}$ & R.A.E & $\mathbf{E}_{\text {def }}$ & $\begin{array}{c}\mathbf{d} E_{\text {ads }} / \mathbf{d N}_{\mathrm{i}} \\
\mathbf{T} 2\end{array}$ & 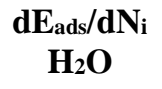 & $\begin{array}{c}\mathbf{d E}_{\text {ads }} / \mathrm{dN}_{\mathrm{i}} \\
\mathrm{HCl}\end{array}$ \\
\hline $\mathrm{T} 2$ & 33.340 & & & & & & \\
\hline $\mathrm{H}_{2} \mathrm{O}$ & 0.030 & & & & & & \\
\hline $\mathrm{HCl}$ & 1.694 & & & & & & \\
\hline $\mathrm{Fe}\left(\begin{array}{lll}1 & 1 & 1\end{array}\right)-1$ & -900.99 & -952.80 & -930.36 & -22.44 & -249.17 & -0.297 & -16.62 \\
\hline $\mathrm{Fe}\left(\begin{array}{lll}1 & 1 & 1\end{array}\right)-2$ & -900.56 & -952.37 & -928.50 & -23.87 & -246.25 & -0.203 & -16.19 \\
\hline $\mathrm{Fe}\left(\begin{array}{lll}1 & 1 & 1\end{array}\right)-3$ & -857.84 & -909.65 & -885.82 & -23.82 & -239.39 & -0.380 & -15.75 \\
\hline $\mathrm{Fe}\left(\begin{array}{lll}1 & 1 & 1\end{array}\right)-4$ & -848.63 & -900.44 & -876.45 & -23.98 & -243.05 & -0.321 & -18.06 \\
\hline $\mathrm{Fe}\left(\begin{array}{lll}1 & 1 & 1\end{array}\right)-5$ & -837.79 & -889.60 & -866.28 & -23.32 & -242.01 & -0.495 & -15.64 \\
\hline $\mathrm{Fe}\left(\begin{array}{lll}1 & 1 & 1\end{array}\right)-6$ & -822.79 & -874.60 & -850.35 & -24.24 & -241.18 & -0.327 & -16.34 \\
\hline $\mathrm{Fe}\left(\begin{array}{lll}1 & 1 & 1\end{array}\right)-7$ & -821.32 & -873.13 & -847.75 & -25.37 & -235.89 & -0.201 & -15.90 \\
\hline $\mathrm{Fe}\left(\begin{array}{lll}1 & 1 & 1\end{array}\right)-8$ & -819.92 & -871.73 & -846.10 & -25.63 & -240.40 & -0.145 & -16.40 \\
\hline $\mathrm{Fe}\left(\begin{array}{lll}1 & 1 & 1\end{array}\right)-9$ & -819.05 & -870.85 & -845.38 & -25.47 & -240.19 & -0.612 & -1.86 \\
\hline $\mathrm{Fe}\left(\begin{array}{lll}1 & 1 & 1\end{array}\right)-10$ & -816.16 & -867.97 & -839.42 & -28.55 & -254.73 & -0.187 & -3.51 \\
\hline
\end{tabular}

The parameters presented in Table 4 include total energy ( $\mathbf{E}_{\text {Total }}$ ) of T2 adsorbed on $\mathrm{Fe}(111)$ in the presence of $50 \mathrm{H}_{2} \mathrm{O}$ and $10 \mathrm{HCl}$, which is defined as the sum of the T2 inhibitor energies, the rigid adsorption energy (RAE), and the deformation energy $\left(E_{\text {def }}\right)$. The substrate energy (iron (111) surface) is taken as zero. In addition, adsorption energy $\left(E_{a d s}\right)$ reports energy in $\mathrm{Kcal} / \mathrm{mol}$, released (or required) when the relaxed inhibitor, $\mathrm{HCl}$ and water molecules are adsorbed on the iron (111) surface. The adsorption energy is defined as the sum of the rigid adsorption energy and the deformation energy for T2 inhibitor. The rigid 
adsorption energy reports the energy in $\mathrm{kcal} / \mathrm{mol}$, released (or required) when the unrelaxed inhibitor and water molecules (i.e., before the geometry optimization step) are adsorbed onto the iron surface. The deformation energy reports the energy in $\mathrm{kcal} / \mathrm{mol}$, released when the adsorbed molecules are relaxed on the substrate surface. Table 4 also shows $\left(\Delta \mathrm{E}_{\text {ads }} / \mathrm{dNi}\right)$, which reports the energy in $\mathrm{kcal} / \mathrm{mol}$, of inhibitor/iron surface configurations, where one of the inhibitors has been removed.

It is quite clear from Table 4 that the value of adsorption energy is negative, which denotes that the adsorption could spontaneously occur. The largest negative adsorption energies value is $-871.73 \mathrm{kcal} / \mathrm{mol}$, indicating the system with the most stable and stronger adsorption [53]. In all cases, the inhibitor adsorption energies are far higher than those of water molecules. This indicates the possibility of gradual substitution of $\mathrm{H}_{2} \mathrm{O}$ and $\mathrm{HCl}$ molecules from the iron surface, resulting in the formation of a stable layer, which can protect the iron from aqueous corrosion (chemical adsorption).

\section{Conclusion}

In this work, we have synthesized a new compound derivative of 2mercaptobenzimidazole, susceptive to present interesting surfactant properties. We have shown that the compound presents a good inhibition property for the corrosion of $\mathrm{C}$-steel in a hydrochloric acid solution; polarization curves have indicated that the inhibitor mainly behaves as a mixed-type inhibitor. EIS has showed that the charge transferring controls the corrosion inhibition process in the uninhibited and inhibited solutions. Different inhibition mechanisms were proposed for T2 molecules, based on their PZC value in the studied conditions. The adsorption of $\mathrm{T} 2$ has followed Langmuir adsorption isotherm model. Dynamic simulation confirms the displacement of water molecules by the organic inhibitor.

\section{References}

1. Hegazy M. J Mol Liq. 2015;208:227-236.

2. Qing W, Xuemei M, Haiyan S, et al. J Chin Soc Corros Prot 2015;35:49-54.

3. Qiu L-G, Xie A-J, Shen Y-H. Mater Chem Phys. 2005;91:269-273.

4. Maayta A, Bitar M, Al-Abdallah M. Br Corros J. 2001;36:133-135.

5. Villamil RF, Corio $\mathrm{P}$, Agostinho SM, et al. J Electroanal Chem. 1999;472:112-119.

6. Branzoi V, Golgovici F, Branzoi F. Mater Chem Phys. 2003;78:122-131.

7. El Aal EA, El Wanees SA, Farouk A, et al. Corros Sci 2013;68:14-24.

8. Serreau L, Beauvais M, Heitz C, et al. J Colloid Interface Sci. 2009;332:382388.

9. Gaysinski M, Le Forestier J, Cambon A, et al. J Fluor Chem. 1997;83:175182.

10. Hosseini M, Mertens SF, Arshadi MR. Corros Sci. 2003; 45:1473-1489.

11. $\mathrm{Mu}$ G, Zhao T, Liu M, et al. Corrosion. 1996; 52:853-856.

12. Elachouri M, Hajji MS, Salem M, et al. Corrosion. 1996;52:103-108. 
13. Zarrouk A, Zarrok H, Salghi R, et al. J Mater Env Sci. 2013;4:177-192.

14. Manssouri M, El Ouadi Y, Znini M, et al. J Mater Env Sci. 2015;6:631-646.

15. Fouda A, Shalabi K, Ezzat R. J Mater Environ Sci. 2015;6:1022-1039.

16. Abdel-Azim A, Milad R, El-Ghazawy R, et al. Egypt J Pet. 2014;23:15-20.

17. Benabdellah M, Tounsi A, Khaled K, et al. Arab J Chem. 2011;4:17-24.

18. Alaoui KI, El Hajjaji F, Azaroual M, et al. J Chem Pharm Res. 2014;6:63-81.

19. Chakib I, Elmsellem H, Sebbar N, et al. J Mater Env Sci. 2016;7:1866-1881.

20. Metropolis N, Rosenbluth AW, Rosenbluth MN, et al. J Chem Phys. 1953;21:1087-1092.

21. Accelrys Inc. san Diego: Materials Studio, Revision 6.0; 2013.

22. Belghiti ME, Karzazi Y, Tighadouini S, et al. J Mater Env Sci. 2016;7:956967.

23. Belghiti ME, Karzazi Y, Dafali A, et al. J Mol Liq. 2016;216:874-886.

24. Karzazi Y, Belghiti M, El-Hajjaji F, Boudra S, Hammouti B. J. Mater. Environ. Sci. 2016; 7:3916-3929.

25. Sun H, Ren P, Fried J. Comput Theor Polym Sci. 1998;8:229-246.

26. Sun H. J Phys Chem B. 1998;102:7338-7364.

27. Lgaz H, Bhat KS, Salghi R, et al. J Mol Liq. 2017;238:71-83.

28. Enumula S, Pangal A, Gazge M, et al. Res J Chem Sci. 2014;4:78-88.

29. El-Hajjaji F, Greche H, Taleb M, et al. J Mater Env Sci. 2016;7:566-578.

30. Retzmann N, Maatz G, Ritter H. Beilstein J Org Chem. 2014;10:2480.

31. El-Hajjaji F, Belkhmima R, Zerga B, et al. Int $\mathrm{J}$ Electrochem Sci. 2014;9:4721-4731.

32. Zouitini, Rodi YK, Elmsellem H, et al. Der Pharm Chemica. 2016;8:23-31.

33. Baba YF, Elmsellem H, Rodi YK, et al. Der Pharm Lettre. 2016;8:128-137.

34. El Ouasif L, Merimi I, Zarrok H. et al. J Mater Env Sci. 2016;7:2718-2730.

35. Bourichi S., Rodi YK, Elmsellem H, et al. Der Pharm Chemica. 2016;8:179186.

36. El-Hajjaji F, Belkhmima R, Zerga B, et al. J Mater Environ Sci. 2014;5:263270.

37. Salim R, Ech-chihbi E, Oudda H, et al. Der Pharm Chemica. 2016;8:200213.

38. Ech-chihbi E, Salim R, Oudda H, et al. Der Pharm Chemica. 2016;8:214230.

39. Aoufir Y, Lgaz H, Bourazmi H, et al. J Mater Env Sci. 2016; 7:4330-4347.

40. Karzazi Y, Belghiti ME, El-Hajjaji F, et al. J Mater Environ Sci. 2016;7:4011-4023.

41. Shawali AS, Abdallah MA, Mosselhi MA, et al. Z Für Naturforschung B. 2002;57:552-556.

42. Khadraoui A, Khelifa A, Hamitouche $\mathrm{H}$, et al. Res Chem Intermed. 2014;40:961-972.

43. Ghazoui A, Benchat N, El-Hajjaji F, et al. J Alloys Compd. 2017;693:510517.

44. Al Mamari K, Elmsellem H, Sebbar N, et al. J Mater Environ Sci. 2016;7:3286-3299

45. Khamis E. Corrosion. 1990;46:476. 
46. El-Rehim SA, Ibrahim MA, Khaled K. J Appl Electrochem. 1999;29:593599.

47. Moretti G, Quartarone G, Tassan A, et al. Mater Corros. 1994;45:641-647.

48. Obot I, Obi-Egbedi N, Umoren S. Int J Electrochem Sci. 2009;4:863-877.

49. Singh AK, Quraishi M. Corros Sci. 2011;53:1288-1297.

50. Donahue FM, Nobe K. J Electrochem Soc. 1965;112:886-891.

51. Khamis E, Bellucci F, Latanision RM, et al. Corrosion. 1991;47:677-686.

52. Ebenso EE, Kabanda MM, Arslan $\mathrm{T}$, et al. Int $\mathrm{J}$ Electrochem Sci. 2012;7:5643-5676.

53. Bousskri A, Lgaz H, Jodeh S, et al. Appl J Environ Eng Sci. 2016;2:1-10. 